\title{
Hydrogen sulfide induced by nitric oxide mediates ethylene-induced stomatal closure of Arabidopsis thaliana
}

\author{
LIU Jing ${ }^{1}$, HOU LiXia ${ }^{1}$, LIU GuoHua ${ }^{1}$, LIU Xin ${ }^{1 *} \&$ WANG XueChen ${ }^{2}$ \\ ${ }^{1}$ Key Laboratory of Plant Biotechnology in Universities of Shandong, Life Sciences College, Qingdao Agricultural University, Qingdao 266109, \\ China; \\ ${ }^{2}$ State Key Laboratory of Plant Physiology and Biochemistry, College of Biological Sciences, China Agricultural University, Beijing 100094, \\ China
}

Received June 15, 2011; accepted September 1, 2011

\begin{abstract}
Pharmacological, laser scanning confocal microscopic (LSCM), real-time PCR and spectrophotographic approaches are used to study the roles of hydrogen sulfide $\left(\mathrm{H}_{2} \mathrm{~S}\right)$ and nitric oxide $(\mathrm{NO})$ in signaling transduction of stomatal movement response to ethylene in Arabidopsis thaliana. In the present study, inhibitors of $\mathrm{H}_{2} \mathrm{~S}$ synthesis were found to block ethylene-induced stomatal closure of Arabidopsis. Treatment with ethylene induced $\mathrm{H}_{2} \mathrm{~S}$ generation and increased $L$-/D-cysteine desulfhydrase (pyridoxalphosphate-dependent enzyme) activity in leaves. Quantitative PCR analysis showed AtL-CDes and AtD-CDes transcripts were induced by ethylene. It is suggested that ethylene-induced $\mathrm{H}_{2} \mathrm{~S}$ levels and $L$-/D-cysteine desulfhydrase activity decreased when $\mathrm{NO}$ was compromised. The data clearly show that ethylene was able to induce $\mathrm{H}_{2} \mathrm{~S}$ generation and stomatal closure in Atnoal plants, but failed in the Atnial,nia2 mutant. Inhibitors of $\mathrm{H}_{2} \mathrm{~S}$ synthesis had no effect on ethylene-induced NO accumulation and nitrate reductase (NR) activity in guard cells or leaves of Arabidopsis, whereas ethylene was able to induce NO synthesis. Therefore, we conclude that $\mathrm{H}_{2} \mathrm{~S}$ and $\mathrm{NO}$ are involved in the signal transduction pathway of ethylene-induced stomatal closure. In Arabidopsis, $\mathrm{H}_{2} \mathrm{~S}$ may represent a novel downstream indicator of $\mathrm{NO}$ during ethylene-induced stomatal movement.
\end{abstract}

hydrogen sulfide, nitric oxide, $L$-/D-cysteine desulfhydrase, Arabidopsis thaliana, ethylene, stomatal closure

Citation: Liu J, Hou L X, Liu G H, et al. Hydrogen sulfide induced by nitric oxide mediates ethylene-induced stomatal closure of Arabidopsis thaliana. Chinese Sci Bull, 2011, 56: 3547-3553, doi: 10.1007/s11434-011-4819-y

Stomata are by far the most influential components in gas exchange and their movements control transpiration [1]. Consequently, stomata are important regulators of plant growth and development. Although previous studies have shown stomata respond to a variety of environmental stresses, such as drought, cold, high $\mathrm{CO}_{2}$ concentration and phytohormone [2], little is known about the signal transduction mechanisms that function in guard cells. The effects of some newly identified signal molecules on regulation of stomatal aperture have not been studied yet.

Ethylene is best known for its roles in the regulation of many developmental processes throughout the plant's life cycle, from germination to senescence, and is also involved

*Corresponding author (email: liuxin6080@yahoo.com.cn) in responses to environmental stimuli such as stress and pathogen attack. It was reported ethylene induces stomatal closure in detached epidermal strips from leaves of Arabidopsis thaliana, and hydrogen peroxide $\left(\mathrm{H}_{2} \mathrm{O}_{2}\right)$ production that originated from $\mathrm{NAD}(\mathrm{P}) \mathrm{H}$ oxidase pathway plays an important role in the ethylene signal transduction leading to stomatal closure [3]. Recently, Liu et al. [3] demonstrated that $\mathrm{H}_{2} \mathrm{O}_{2}$-regulated nitric oxide (NO) production involves ethylene-induced stomatal closure, NO production was associated with nitrate reductase (NR) activity, and the nitric oxide synthase (NOS) inhibitor $L$-NAME had little effect on ethylene-induced NO synthesis. It is indicated that transient changes of calcium [4] and alkalization of the cytoplasm [5] enhanced NO generating in ethylene-induced stomatal closure. The signal transport pathway for regulation of 
stomatal movement by ethylene is a complex signaling network, which includes calcium, protons, $\mathrm{NO}, \mathrm{H}_{2} \mathrm{O}_{2}$, and several other components. Cross reactions are known to exist between these signaling molecules. Further studies of signal transduction mechanisms of ethylene-induced stomatal closure are needed to understand the mechanism of stomatal closure.

Hydrogen sulfide $\left(\mathrm{H}_{2} \mathrm{~S}\right)$ and its counterparts $\mathrm{NO}$ and carbon monoxide $(\mathrm{CO})$ are increasingly recognized as "gasotransmitters". Accumulating evidence shows that $\mathrm{H}_{2} \mathrm{~S}$ participates in a variety of biological processes in plants [6-8]. In higher plants, cysteine desulfhydrase catalyzes the formation of $L$-alanine and elemental sulfur or $\mathrm{H}_{2} \mathrm{~S}$ from $L$-cysteine. For this reaction, two mechanisms are possible: elemental sulfur is released enzymatically from $L$-cysteine and reduced to sulfide non-enzymatically with $L$-cysteine or dithiothreitol contained in the reaction mixture. Recently, a review of $\mathrm{H}_{2} \mathrm{~S}$ in plants was published, and $\mathrm{H}_{2} \mathrm{~S}$ emission by higher plants has been observed to inhibit the damage of pathogen attack [9]. However, it remains unclear whether $\mathrm{H}_{2} \mathrm{~S}$ serves as a signal molecule during regulated stomatal movement. It was reported that $\mathrm{NO}$ donors induce $\mathrm{H}_{2} \mathrm{~S}$ synthesis in rat aortic tissue and enhance the expression of cystathionine- $\gamma$-lyase (CSE) [10]. Zhang et al. [11] reported the process of $\mathrm{H}_{2} \mathrm{~S}$-induced adventitious root formation was probably mediated by $\mathrm{NO}$ signals and $\mathrm{H}_{2} \mathrm{~S}$ might act upstream of NO signal pathways. Thus the regulation of stomatal conductance is extremely complex. Is there an interaction between $\mathrm{H}_{2} \mathrm{~S}$, $\mathrm{NO}$ and other signaling molecules? To address this question, Arabidopsis genotypes (wild type, Atl-cdes, Atd-cdes, Atnoal and Atnial,nia2 mutants) were used to assess the importance and interactions of $\mathrm{H}_{2} \mathrm{~S}$ and NO during stomatal responses to ethylene.

\section{Materials and methods}

\subsection{Chemicals}

The following buffers and solutions were used: MES-KOH buffer $\left(10 \mathrm{mmol} / \mathrm{L} \mathrm{MES,} 50 \mathrm{mmol} / \mathrm{L} \mathrm{KCl}, 0.1 \mu \mathrm{mol} / \mathrm{L} \mathrm{CaCl}_{2}\right.$, $\mathrm{pH} 6.1) ; 20 \mathrm{mmol} / \mathrm{L}$ Tris- $\mathrm{HCl} ; 2.5 \mathrm{mmol} / \mathrm{L}$ dithiothreitol (DTT); $0.8 \mathrm{mmol} / \mathrm{L} L$-cysteine (Sigma, USA); $0.8 \mathrm{mmol} / \mathrm{L}$ $D$-cysteine (Sigma); $30 \mathrm{mmol} / \mathrm{L} \quad \mathrm{FeCl}_{3} ; 20 \mathrm{mmol} / \mathrm{L}$ $N, N$-dimethyl- $p$-phenylenediamine dihydrochloride; 0.2 $\mathrm{mmol} / \mathrm{L}$ 2-(4-carboxyphenyl)-4,4,5,5-tetramethyl imidazoline-1-oxyl-3-oxide potassium salt (cPTIO; Sigma); 0.025 $\mathrm{mmol} / \mathrm{L} N \omega$-nitro- $L$-arginine methyl ester ( $L$-NAME; Sigma); $10 \mu \mathrm{mol} / \mathrm{L}$ 4,5-diaminofluorescein diacetate (DAF-2DA; Sigma); 0.004\% ethephon (Sigma); $0.1 \mathrm{mmol} / \mathrm{L} \mathrm{Na}_{2} \mathrm{WO}_{4} ; 0.4$ $\mathrm{mmol} / \mathrm{L}$ aminooxy acetic acid (AOA; Sigma); $0.2 \mathrm{mmol} / \mathrm{L}$ potassium pyruvate $\left(\mathrm{C}_{3} \mathrm{H}_{3} \mathrm{KO}_{3}\right) ; 0.2 \mathrm{mmol} / \mathrm{L} \mathrm{NH} \mathrm{NH}_{3}$; and 0.4 $\mathrm{mmol} / \mathrm{L} \mathrm{NH}_{2} \mathrm{OH}$.

\subsection{Plant materials}

Arabidopsis thaliana ecotype Columbia (Col-0) was used throughout this study. Seeds of the AtL-CDes T-DNA insertion line (SALK_041918, designated Atl-cdes) and AtDCDes T-DNA insertion line (CS853264, designated Atdcdes) were obtained from The Arabidopsis Information Resource (TAIR, USA). Atnoal was obtained from Prof. Yingzhang Li (China Agricultural University), and the Atnial,nia2 mutant was obtained from Prof. Yuling Chen (Hebei Normal University). Seeds were surface-sterilized with $10 \%$ bleach and sown on Murashige and Skoog (MS) medium. Plates were stratified in darkness for $2-4 \mathrm{~d}$ at $4^{\circ} \mathrm{C}$ and then transferred to a tissue culture room at $22-25^{\circ} \mathrm{C}$ under a $16 \mathrm{~h} / 8 \mathrm{~h}$ day/night photoperiod. After 1 week, seedlings were potted in soil and placed in a growth chamber at $22-25^{\circ} \mathrm{C}, 70 \% \mathrm{RH}$, and $120 \mu \mathrm{mol} \mathrm{m} \mathrm{s}^{-2}$ under a $16 \mathrm{~h} / 8 \mathrm{~h}$ day/night photoperiod.

\subsection{Stomatal bioassay}

Stomatal bioassays were performed as described by Liu et al. [3] with minor modifications. The abaxial epidermis was peeled from the leaves of 3- to 4-week-old plants. Epidermal peels were floated, peeled-side down, in MES-KOH buffer and incubated under light $\left(200 \mu \mathrm{mol} \mathrm{m} \mathrm{m}^{-2}\right)$ to stimulate stomatal opening. Epidermal peels with preopened stomata were transferred to the same buffer supplemented with different treatments (ethephon, ethephon with $\left.\mathrm{C}_{3} \mathrm{H}_{3} \mathrm{KO}_{3}+\mathrm{NH}_{3}, \mathrm{NH}_{2} \mathrm{OH}, \mathrm{AOA}\right)$ for $30 \mathrm{~min}$. The width of the stomatal aperture was measured using a light microscope with the help of a precalibrated ocular micrometer. Ten apertures were monitored at random in three different epidermal strips from each treatment. The data presented are the means \pm SE of 90 measurements.

\subsection{Quantitative RT-PCR analysis}

Total RNA were extracted with the TRIzol reagent (Invitrogen, USA) following the manufacturer's instructions. For real-time PCR analysis, first-strand cDNA was synthesized from $3 \mu \mathrm{g}$ total RNA using M-MLV reverse transcriptase (TaKaRa, Japan). After synthesis of the first-strand cDNA using oligo d(T)18 primer (TaKaRa), real-time PCR was performed using the MyiQ Real-Time PCR Detection System (Bio-Rad, USA) in the presence of SYBR Green I (BioWhittaker Molecular Applications) in the amplification mixture according to the manufacturer's protocols. Specific primer sets were designed for AtL-CDes (forward primer 5'-TGTATGTGAGGAGGAGGC-3', reverse primer 5'-GTTTCATACTGATGCTGCTC-3') and AtD-CDes (forward primer 5'-ATAGAAGCAGCAAGGGAA-3', reverse primer 5'-TGAGGCTCTTACTAATGCT-3'). Amplification of actin transcripts served as the internal standard. The data were analyzed using MyiQ software (Bio-Rad).

\subsection{Measurement of $\mathrm{H}_{2} \mathrm{~S}$ emission}

Measurement of $\mathrm{H}_{2} \mathrm{~S}$ emission was performed as described by Sekiya et al. [12] with minor modifications. Plant mate- 
rials were frozen in liquid nitrogen and crushed with a mortar and pestle. The soluble proteins were extracted by addition of $0.9 \mathrm{~mL}$ of $20 \mathrm{mmol} / \mathrm{L}$ Tris- $\mathrm{HCl}(\mathrm{pH} 8.0)$ to $0.1 \mathrm{~g}$ plant material, which was treated by $0.004 \%$ ethephon for periods of $0,1,2,4,6$, or $8 \mathrm{~h}$. After centrifugation, the protein content of the supernatant was adjusted to a concentration of $100 \mu \mathrm{g} / \mathrm{mL}$ to obtain equal amounts of protein in each assay sample. Then $\mathrm{H}_{2} \mathrm{~S}$ was absorbed into a zinc acetate trap located at the bottom of the test tube. After reaction for $30 \mathrm{~min}$ at $37^{\circ} \mathrm{C}, 100 \mu \mathrm{L}$ of $30 \mathrm{mmol} / \mathrm{L} \mathrm{FeCl}_{3}$ dissolved in $1.2 \mathrm{~mol} / \mathrm{L} \mathrm{HCl}$ was added to the trap. A volume of 100 $\mu \mathrm{L}$ of $20 \mathrm{mmol} / \mathrm{L} N, N$-dimethyl- $p$-phenylenediamine dihydrochloride dissolved in $7.2 \mathrm{~mol} / \mathrm{L} \mathrm{HCl}$ was injected into the trap. The amount of $\mathrm{H}_{2} \mathrm{~S}$ in the zinc acetate trap was determined colorimetrically at $670 \mathrm{~nm}$.

\section{6 $L$-/D-cysteine desulfhydrase activity measurements}

$L$-/D-cysteine desulfhydrase activity measurements were performed as described by Riemenschneider et al. [13]. Plant material was frozen in liquid nitrogen and crushed using a mortar and pestle. The soluble proteins were extracted over a period of $4 \mathrm{~h}$ by addition of $0.9 \mathrm{~mL}$ of 20 $\mathrm{mmol} / \mathrm{L}$ Tris- $\mathrm{HCl}(\mathrm{pH} 8.0)$ to $0.1 \mathrm{~g}$ plant material. After centrifugation, the protein content of the supernatant was adjusted to $100 \mu \mathrm{g} / \mathrm{mL}$ to provide an equal amount of protein in each assay sample. $L$-cysteine desulfhydrase activity was measured by the release of $\mathrm{H}_{2} \mathrm{~S}$ from $L$-cysteine in the presence of DTT. The $1 \mathrm{~mL}$ assay included: $0.8 \mathrm{mmol} / \mathrm{L}$ $L$-cysteine, $2.5 \mathrm{mmol} / \mathrm{L}$ DTT, $100 \mathrm{mmol} / \mathrm{L}$ Tris- $\mathrm{HCl}(\mathrm{pH}$ 9.0), and $10 \mu \mathrm{g}$ protein. The reaction was initiated by the addition of $L$-cysteine. After incubation for $15 \mathrm{~min}$ at $37^{\circ} \mathrm{C}$, the reaction was terminated by addition of $100 \mu \mathrm{L}$ of 30 $\mathrm{mmol} / \mathrm{L} \mathrm{FeCl}_{3}$ dissolved in $1.2 \mathrm{~mol} / \mathrm{L} \mathrm{HCl}$ and $100 \mu \mathrm{L}$ of 20 mmol/L $N, N$-dimethyl- $p$-phenylenediamine dihydrochloride dissolved in $7.2 \mathrm{~mol} / \mathrm{L} \mathrm{HCl}$. The formation of methylene blue was determined at $670 \mathrm{~nm}$.

$D$-cysteine desulfhydrase activity was determined using the same method, except that $D$-cysteine was used instead of $L$-cysteine and the $\mathrm{pH}$ of the Tris- $\mathrm{HCl}$ buffer was 8.0.

All results are expressed as means \pm SE of three duplications.

\subsection{Detection of NO in guard cells}

Measurement of NO in guard cells was performed as dtscribed by Gonugunta et al. [14] with minor modifications. The abaxial epidermis was peeled from rosette leaves of 3to 4-week-old plants and treated with MES-KOH buffer. The epidermal strips were incubated in the dark for $20 \mathrm{~min}$ with $10 \mu \mathrm{mol} / \mathrm{L}$ of the fluorescent probe DAF-2DA (Sigma) to detect NO. Excess dye was removed by three washes with incubation buffer. Cells were observed using a confocal laser scanning microscope equipped with a camera (excitation at $488 \mathrm{~nm}$, emission at 505-530 nm; Zeiss LSM 510 META). Images were analyzed using LSM 5 Image
Browser software. We observed 15-30 guard cells per experiment in each treatment. Each experiment consisted of at least three independent replicates.

\subsection{NO level and NOS activity in leaves}

We determined NO level and NOS activity in the leaves using a kit provided by the Nanjing Jiancheng Bioengineering Institute of China.

\subsection{NR activity measurement in leaves}

The activity of NR in the leaves was determined using the method described in Ref. [15] with minor modifications. All results are expressed as the mean $\pm \mathrm{SE}$ of three duplicates.

\section{Results}

\subsection{Involvement of $\mathrm{H}_{2} \mathrm{~S}$ in ethylene-induced stomatal closure}

(i) Effects of $\mathrm{H}_{2} \mathrm{~S}$ synthesis inhibitors on ethylene-induced stomatal closure, $\mathrm{H}_{2} \mathrm{~S}$ concentrations and $L$-/D-cysteine desulfhydrase activity. Treatment with $0.004 \%$ ethephon caused stomatal closure (Figure 1(a)). In addition, ethephon caused a marked increase in the $\mathrm{H}_{2} \mathrm{~S}$ level of $A$. thaliana leaves (Figure 1(b)). Inhibitors of $\mathrm{H}_{2} \mathrm{~S}$ synthesis and the production of $L$-/D-cysteine desulfhydrase reduced ethylene-induced stomatal closure (Figure $1(\mathrm{a})$ ) and $\mathrm{H}_{2} \mathrm{~S}$ production (Figure 1(b)) in A. thaliana.

To identify further the metabolic pathways involved in $\mathrm{H}_{2} \mathrm{~S}$ synthesis, $L$ - and $D$-cysteine desulfhydrase activity was determined. The presence of $\mathrm{AOA}, \mathrm{NH}_{2} \mathrm{OH}$, or $\mathrm{C}_{3} \mathrm{H}_{3} \mathrm{KO}_{3}+$ $\mathrm{NH}_{3}$ blocked the ethylene-induced synthesis of $\mathrm{H}_{2} \mathrm{~S}$ and caused a marked increase in $L$ - and/or $D$-cysteine desulfhydrase activity. However, when inhibitors of $\mathrm{H}_{2} \mathrm{~S}$ synthesis were applied without ethylene, no effect was observed (Figure 1(c),(d)). These data imply that both $L$ - and $D$-cysteine desulfhydrase activities are implicated in ethylene-induced $\mathrm{H}_{2} \mathrm{~S}$ production in A. thaliana.

(ii) Effects of ethylene on stomatal aperture size in wildtype Arabidopsis thaliana, Atl-cdes and Atd-cdes mutants. To evaluate further the effects of $\mathrm{H}_{2} \mathrm{~S}$ on ethylene-induced stomatal closure in A. thaliana, epidermal peels of Atl-cdes and Atd-cdes mutants were treated with $0.004 \%$ ethephon. The Atl-cdes and Atd-cdes T-DNA insertion lines showed no difference in stomatal aperture size from wild-type plants (Figure 2).

\subsection{NO requirement for ethylene-induced $\mathrm{H}_{2} \mathrm{~S}$ emission}

(i) Effects of NO scavenger and NO synthesis inhibitors on ethylene-induced $\mathrm{H}_{2} \mathrm{~S}$ concentration and $L$ - $/ D$-cysteine desulfhydrase activity. $\mathrm{H}_{2} \mathrm{~S}$ and $\mathrm{NO}$ are involved in the signal transduction pathway of ethylene-induced stomatal closure. To analyze the interactions between $\mathrm{H}_{2} \mathrm{~S}$ and $\mathrm{NO}$, $\mathrm{H}_{2} \mathrm{~S}$ content and activities of $L$ - and $D$-cysteine desulfhydrase were determined after application of cPTIO, $\mathrm{Na}_{2} \mathrm{WO}_{4}$, 

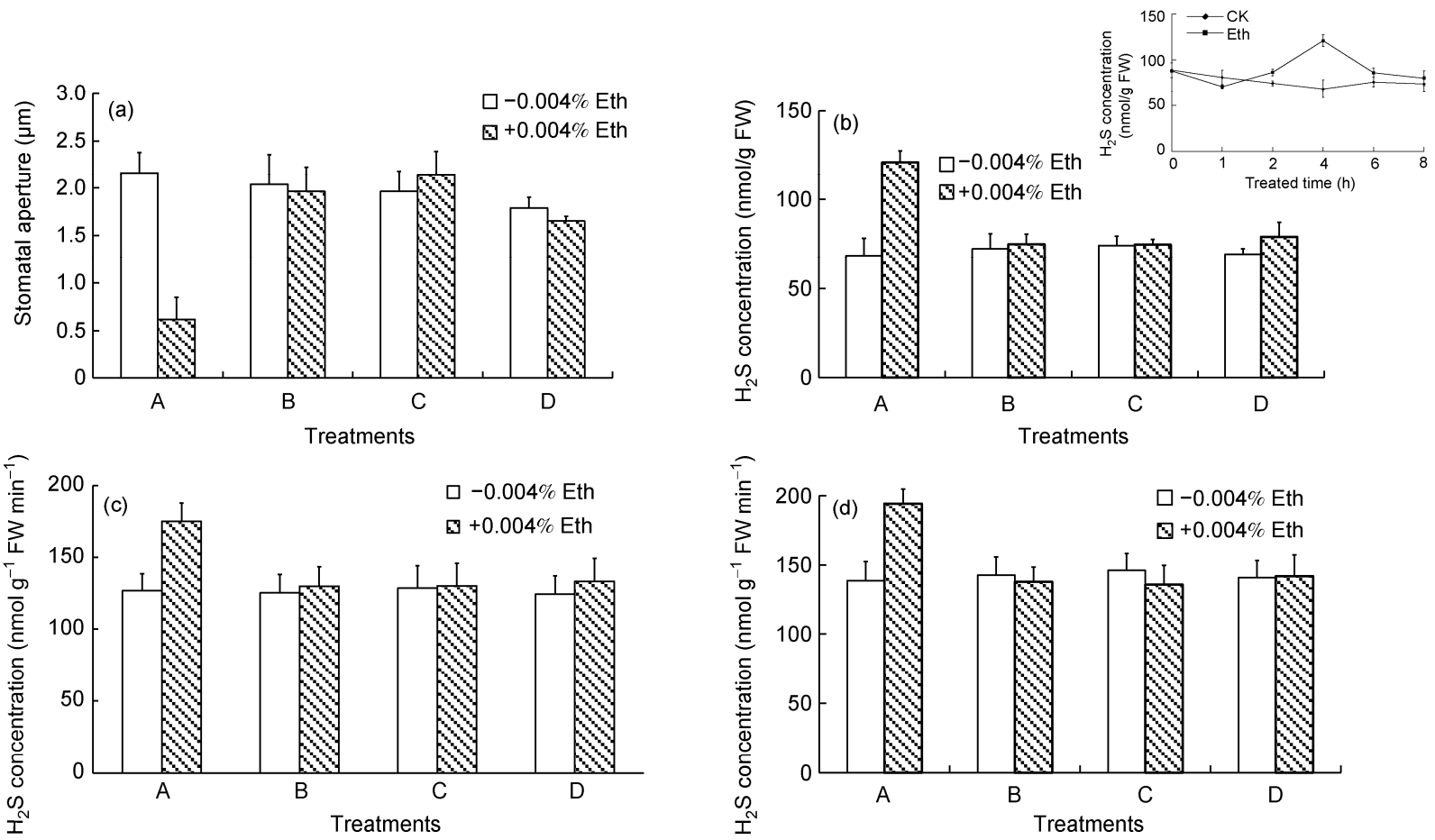

Figure 1 Effects of $\mathrm{H}_{2} \mathrm{~S}$ synthesis inhibitors on ethylene-induced stomatal closure (a), $\mathrm{H}_{2} \mathrm{~S}$ concentration (b) and $L$-/D-cysteine desulfhydrase activity (c and d) in Arabidopsis thaliana. Treatments: A, CK; B, $0.4 \mathrm{mmol} / \mathrm{L}$ AOA; C, $0.4 \mathrm{mmol} / \mathrm{L} \mathrm{NH} \mathrm{H}_{2} \mathrm{OH} ; \mathrm{D}, 0.2 \mathrm{mmol} / \mathrm{L} \mathrm{C}_{3} \mathrm{H}_{3} \mathrm{KO}_{3}+0.2 \mathrm{mmol} / \mathrm{L} \mathrm{NH}$. Iconograph: Time course of the effect of $0.004 \%$ ethyleneon on $\mathrm{H}_{2} \mathrm{~S}$ content in Arabidopsis thaliana leaves.

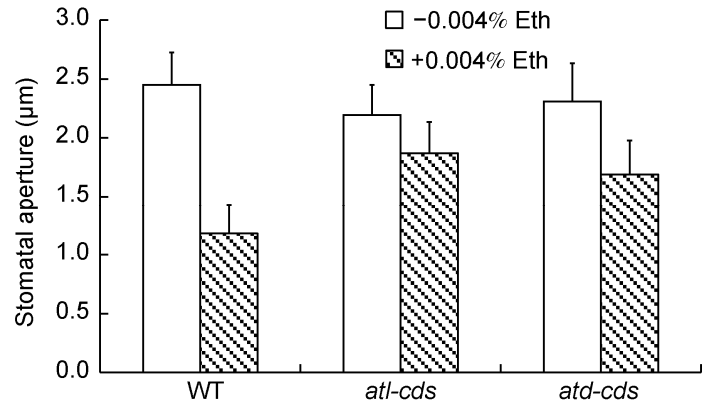

Figure 2 Effects of $0.004 \%$ ethephon on stomatal aperture size in wildtype Arabidopsis thaliana, Atl-cdes and Atd-cdes mutants.

and $L$-NAME. Both cPTIO and $\mathrm{Na}_{2} \mathrm{WO}_{4}$ decreased $\mathrm{H}_{2} \mathrm{~S}$ production (Figure 3 ) and reduced the $L$-/D-cysteine desulfhydrase activity (Figure 4) in the leaves. In contrast, $L$-NAME had no significant effect on ethylene-induced $\mathrm{H}_{2} \mathrm{~S}$ synthesis.

(ii) Effects of NO scavenger and NO synthesis inhibitors on expression of AtL-CDes and AtD-CDes in leaves exposed to ethephon. Expression of AtL-CDes and AtD-CDes was determined after application of a NO donator, SNP, a NO scavenger, cPTIO, a NO inhibitor, $\mathrm{Na}_{2} \mathrm{WO}_{4}$, and a NOS inhibitor, L-NAME. The data showed that AtL-CDes and $A t D-C D e s$ expression were increased after treatment with $0.004 \%$ ethylene, and maximum express level of AtL-CDes and $A t D-C D e s$ were reached at 120 and 30 min respectively (data not shown). SNP enhanced this effect, cPTIO and $\mathrm{Na}_{2} \mathrm{WO}_{4}$ inhibited AtL-CDes and AtD-CDes expression by

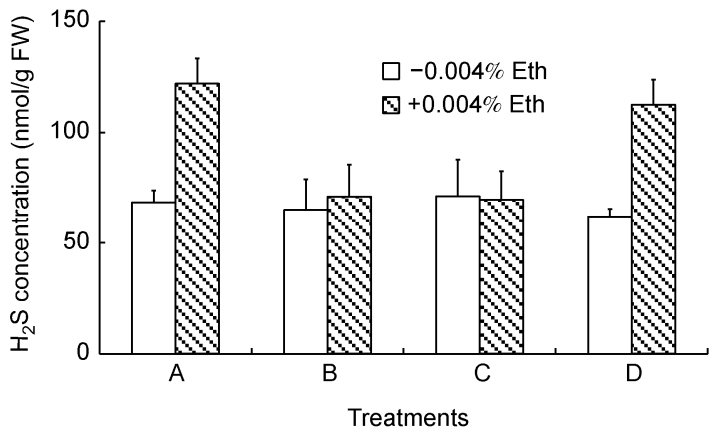

Figure 3 Effects of NO scavenger and NO synthesis inhibitors on ethylene-induced $\mathrm{H}_{2} \mathrm{~S}$ concentration. Treatments: A, CK; B, $0.2 \mathrm{mmol} / \mathrm{L}$ cPTIO; C, $0.1 \mathrm{mmol} / \mathrm{L} \mathrm{Na}_{2} \mathrm{WO}_{4}$; D, $0.025 \mathrm{mmol} / \mathrm{L} L$-NAME.

ethylene, while $L$-NAME had little effect (Figure 5).

(iii) Effects of ethylene on $\mathrm{H}_{2} \mathrm{~S}$ concentrations in the wild-type and Atnoal and Atnial,nia2 mutants. In response to ethephon treatment, the $\mathrm{H}_{2} \mathrm{~S}$ level in leaves of the Atnoal mutant was comparable to that of wild-type plants. However, ethephon had no clear effects in the Atnial,nia2 mutant (Figure 6).

\subsection{NO function downstream of $\mathrm{H}_{2} \mathrm{~S}$ in ethylene- induced stomatal closure}

(i) Effects of $\mathrm{H}_{2} \mathrm{~S}$ synthesis inhibitors on ethephon-induced NO production, NR activity, and NOS activity in Arabidopsis thaliana leaves. To investigate further the interaction between $\mathrm{NO}$ and $\mathrm{H}_{2} \mathrm{~S}$ in ethylene-induced stomatal closure, 

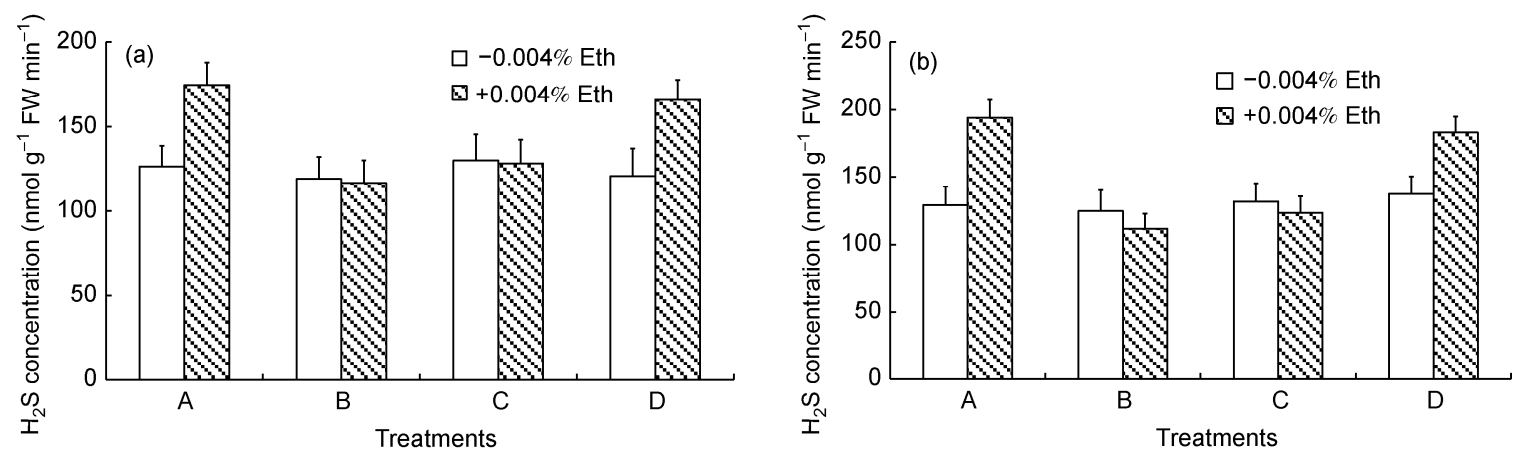

Figure 4 Effects of NO scavenger and NO synthesis inhibitors on ethylene-induced $L$-(a)/D-(b)cysteine desulfhydrase activity. Treatments: A, CK; B, 0.2 $\mathrm{mmol} / \mathrm{L} \mathrm{cPTIO} ; \mathrm{C}, 0.1 \mathrm{mmol} / \mathrm{L} \mathrm{Na} \mathrm{WO}_{4} ; \mathrm{D}, 0.025 \mathrm{mmol} / \mathrm{L} L$-NAME.
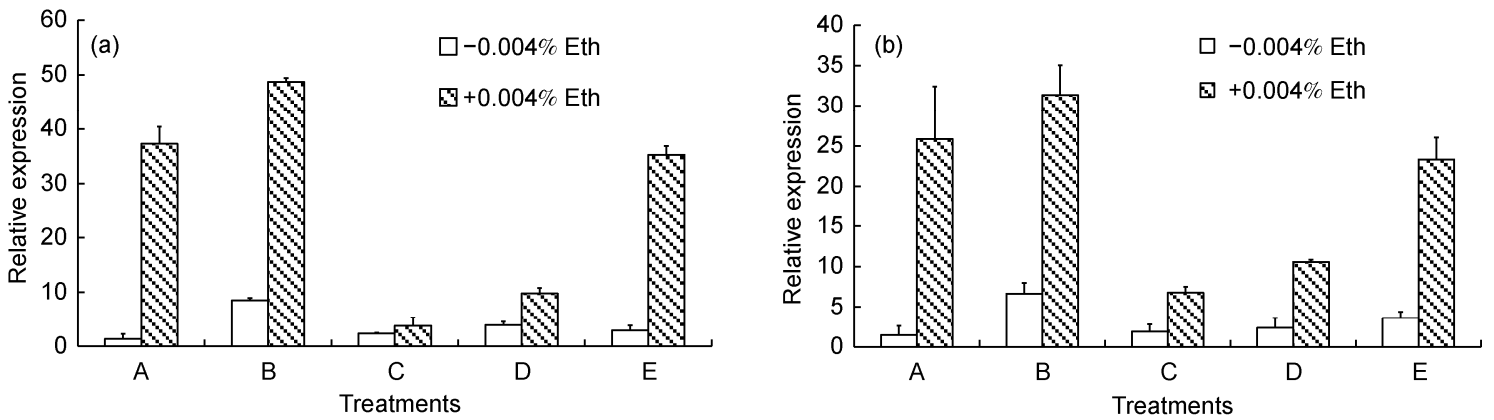

Figure 5 Effects of NO scavenger and NO synthesis inhibitors on expression of AtL-CDes (a) and AtD-CDes (b) in leaves of Arabidopsis thaliana exposed to $0.004 \%$ ethephon. Treatments: A, CK; B, $0.1 \mathrm{mmol} / \mathrm{L} \mathrm{SNP}$; C, $0.2 \mathrm{mmol} / \mathrm{L}$ cPTIO; D, $0.1 \mathrm{mmol} / \mathrm{L} \mathrm{Na} 2 \mathrm{WO}_{4} ; \mathrm{E}, 0.025 \mathrm{mmol} / \mathrm{L} L$-NAME.

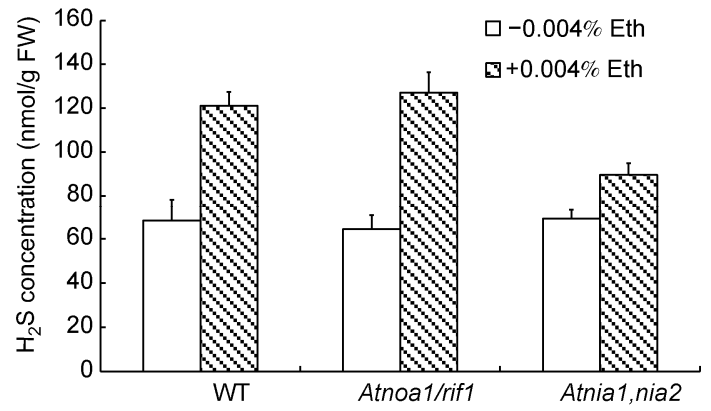

Figure 6 Effects of ethylene on $\mathrm{H}_{2} \mathrm{~S}$ concentration in leaves of wild-type Arabidopsis thaliana, and Atnoal and Atnial,nia2 mutants.

NO content and activities of NR and NOS were determined after application of $\mathrm{AOA}, \mathrm{NH}_{2} \mathrm{OH}$ and $\mathrm{C}_{3} \mathrm{H}_{3} \mathrm{KO}_{3}+\mathrm{NH}_{3}$. None of these compounds affected ethylene-induced NO level in guard cell (Figure 7(a)) and in leavers (Figure 7(b)), or enhanced NR activity (Figure 8(a)). The data indicated that the action of $\mathrm{NO}$ could be upstream of $\mathrm{H}_{2} \mathrm{~S}$. However, ethylene cannot enhance NOS activity (Figure 8(b)), supporting that ethylene induces NO synthesis via promotion of NR activity.

(ii) Effects of ethylene on NO levels in guard cells of the wild-type, and Atl-cdes and Atd-cdes mutants. The fluorescence probe DAF-2DA was used to determine the changes in NO levels in guard cells of the wild type, and Atl-cdes and Atd-cdes mutants, exposed to ethephon.
Treatment with ethephon caused a marked increase in the NO levels of guard cells (Figure 9). Ethephon caused stomatal closure in the wild-type. In contrast, ethephon had no effect on stomatal closure in the Atl-cdes and Atd-cdes mutants (Figure 9).

\section{Discussion}

That $\mathrm{H}_{2} \mathrm{~S}$ might operate as an endogenous neurotransmitter was first suggested in 1996 by Abe and Kimura [16] who described the enzymatic mechanism of $\mathrm{H}_{2} \mathrm{~S}$ production in human brain. Similar to $\mathrm{NO}$ and $\mathrm{CO}, \mathrm{H}_{2} \mathrm{~S}$ is lipophilic and freely permeates plasma membranes, although because of partial dissociation membranes are relatively less permeable to $\mathrm{H}_{2} \mathrm{~S}$ than to both other gases [16]. $\mathrm{H}_{2} \mathrm{~S}$ is increasingly recognized as a member of a growing group of "gasotransmitters", together with its two counterparts, NO and CO. However, little is known about $\mathrm{H}_{2} \mathrm{~S}$ as a signaling molecule in plants. Recently, it was shown a novel $\mathrm{H}_{2} \mathrm{~S}$ donor caused stomatal opening [17]. It is well known that ethylene causes stomatal closure in A. thaliana [2]. However, it is not known whether $\mathrm{H}_{2} \mathrm{~S}$ is involved in the process of ethylene-induced stomatal closure. In the present work, it is shown that the levels of AtL-CDes and AtD-CDes transcripts reached maximum values after treatment with ethylene (Figure 5). The presence of inhibitors of $\mathrm{H}_{2} \mathrm{~S}$ synthesis 

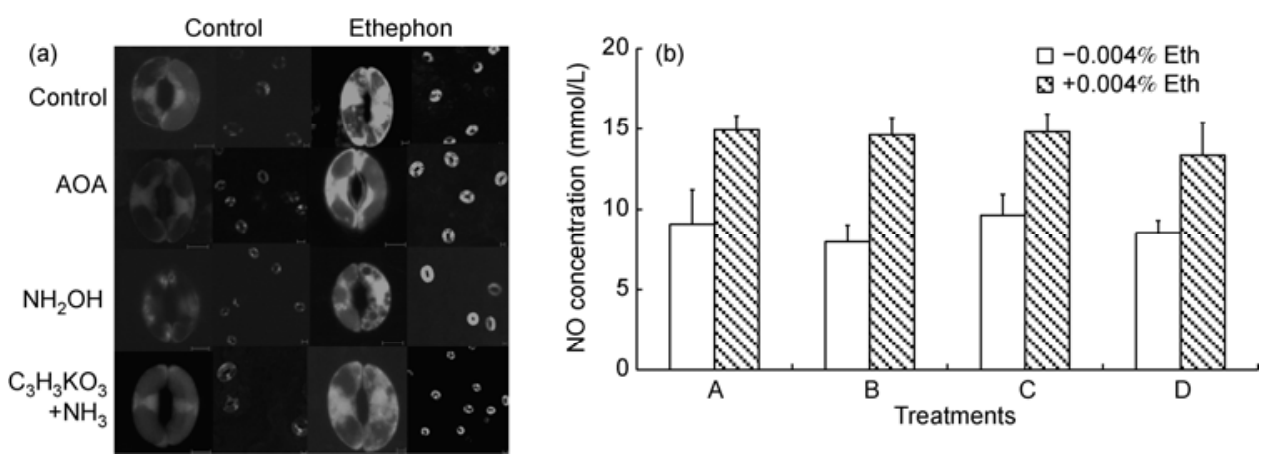

Figure 7 Effects of $\mathrm{H}_{2} \mathrm{~S}$ synthesis inhibitors on ethephon-induced NO production in guard cells (a) or in leaves of Arabidopsis thaliana (b). Treatments: A, $\mathrm{CK}$; B, $0.4 \mathrm{mmol} / \mathrm{L}$ AOA; C, $0.4 \mathrm{mmol} / \mathrm{L} \mathrm{NH}{ }_{2} \mathrm{OH} ; \mathrm{D}, 0.2 \mathrm{mmol} / \mathrm{L} \mathrm{C}_{3} \mathrm{H}_{3} \mathrm{KO}_{3}+0.2 \mathrm{mmol} / \mathrm{L} \mathrm{NH}_{3}$.
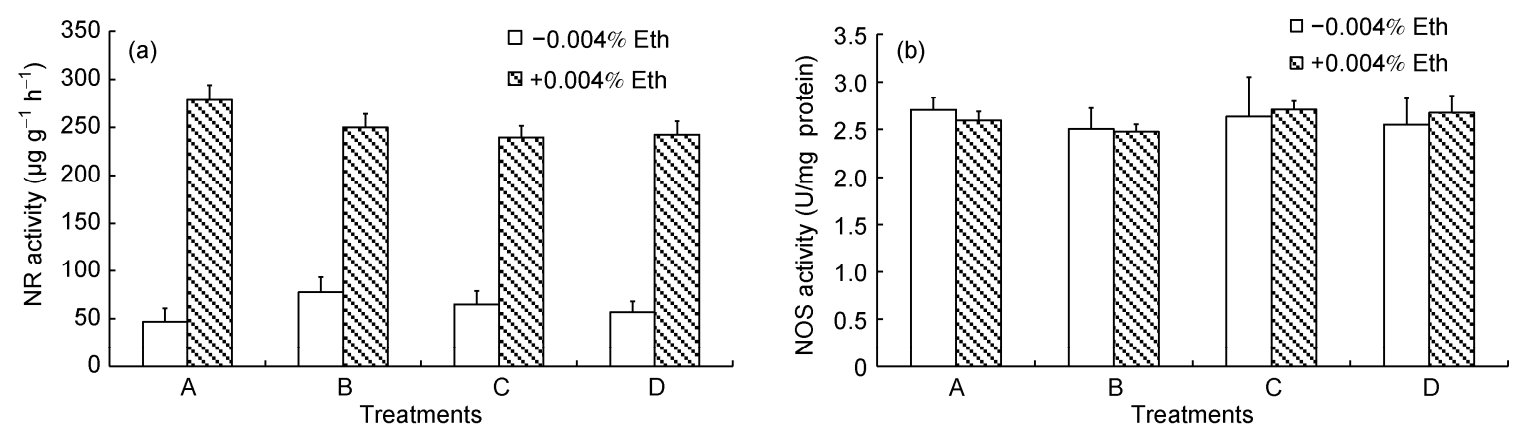

Figure 8 Effects of $\mathrm{H}_{2} \mathrm{~S}$ synthesis inhibitors on ethephon-induced NR activity (a) and NOS activity (b) in Arabidopsis thaliana leaves. Treatments: A, CK; $\mathrm{B}, 0.4 \mathrm{mmol} / \mathrm{L}$ AOA; C, $0.4 \mathrm{mmol} / \mathrm{L} \mathrm{NH} \mathrm{NH}_{2} \mathrm{OH}$, $0.2 \mathrm{mmol} / \mathrm{L} \mathrm{C}_{3} \mathrm{H}_{3} \mathrm{KO}_{3}+0.2 \mathrm{mmol} / \mathrm{L} \mathrm{NH}$.

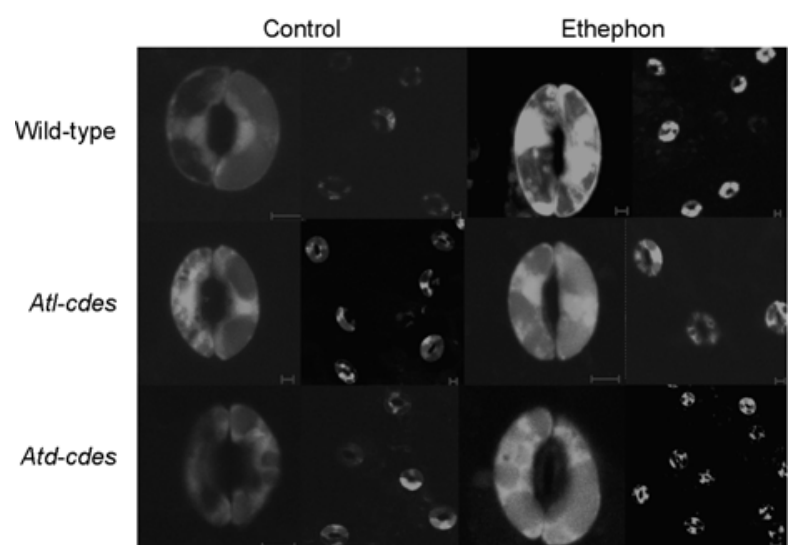

Figure 9 Effects of $0.004 \%$ ethephon on NO levels in guard cells of wild-type Arabidopsis thaliana, and Atl-cdes and Atd-cdes mutants.

(AOA and $\mathrm{NH}_{2} \mathrm{OH}$ ) and of production of $L$ - and $D$-cysteine desulfhydrase $\left(\mathrm{C}_{3} \mathrm{H}_{3} \mathrm{KO}_{3}+\mathrm{NH}_{3}\right)$ decreased ethyleneinduced stomatal closure (Figure 1(a)) and diminished $\mathrm{H}_{2} \mathrm{~S}$ production (Figure 1(b)). Ethephon had no effect on stomatal aperture size in the Atl-cdes and Atd-cdes mutants (Figure 2). These results imply that $\mathrm{H}_{2} \mathrm{~S}$ is required for ethylene-induced stomatal closure.

As a signaling molecule, NO has been demonstrated to be involved in many developmental, physiological and metabolic processes in plants [18]. Using Arabidopsis [3] and Vicia faba [4], we investigated whether NO that acted via a NR-independent route is involved in ethylene-induced stomatal closure. $\mathrm{NO}$ and $\mathrm{H}_{2} \mathrm{~S}$ have wide-ranging effects in diverse aspects of physiological processes, which is indicative of a close relationship between these two signaling molecules in animals. Although exogenously applied $\mathrm{H}_{2} \mathrm{~S}$ alone relaxed smooth muscles, much lower concentrations of $\mathrm{H}_{2} \mathrm{~S}$ greatly enhanced smooth muscle relaxation induced by NO in the thoracic aorta [19]. However, it remains unclear whether there is an interaction between $\mathrm{H}_{2} \mathrm{~S}$ and $\mathrm{NO}$ in ethylene-induced stomatal closure in A. thaliana. The data presented herein clearly show that the NO scavenger cPTIO and the $\mathrm{NR}$ inhibitor $\mathrm{Na}_{2} \mathrm{WO}_{4}$ prevented $\mathrm{H}_{2} \mathrm{~S}$ production (Figure 3 ) and $L-/ D$-cysteine desulfhydrase activity (Figure 4 ), as well as the transcript levels of AtL-CDes and AtDCDes (Figure 5), induced by ethylene. After treatment with ethylene the $\mathrm{H}_{2} \mathrm{~S}$ level in leaves of the Atnoal mutant was comparable to that of wild-type plants, whereas no significant effect was observed in the Atnial, nia2 mutant (Figure 6). In addition, $\mathrm{AOA}, \mathrm{NH}_{2} \mathrm{OH}$, and $\mathrm{C}_{3} \mathrm{H}_{3} \mathrm{KO}_{3}+\mathrm{NH}_{3}$ had no significant effect on ethylene-induced NO synthesis (Figure 7) or NR activity (Figure 8(a)), and no effect in the Atl-cdes and Atd-cdes mutants (Figure 9). These results indicate that the action of $\mathrm{NO}$ could be upstream of $\mathrm{H}_{2} \mathrm{~S}$ during stomatal closure induced by ethylene. However, Zhang et al. [11] reported that the process of $\mathrm{H}_{2} \mathrm{~S}$-induced adventitious root formation was probably mediated by $\mathrm{NO}$ signals and $\mathrm{H}_{2} \mathrm{~S}$ might act upstream of NO signaling pathways [11]. In con- 
clusion, our results indicate that ethylene induces NO synthesis via promotion of NR activity, which leads to $L$-/D-cysteine desulfhydrase-derived $\mathrm{H}_{2} \mathrm{~S}$ production and stomatal closure.

The signal transport pathway for regulation of stomatal movement by ethylene is reported to be a complex signaling network, which includes calcium, protons, $\mathrm{NO}, \mathrm{H}_{2} \mathrm{O}_{2}$, and several other components. For instance, the marked prevention of ABA-induced stomatal closure by EGTA (a calcium chelator) suggested that cytosolic $\mathrm{Ca}^{2+}$ is necessary during stomatal closure by ethylene [4]. Ethylene-induced $\mathrm{H}_{2} \mathrm{O}_{2}$ production that originated from $\mathrm{NAD}(\mathrm{P}) \mathrm{H}$ oxidase and cell wall peroxidase activity plays an important role in the ethylene-induced NO synthesis that leads to stomatal movement [3]. NO generated upstream during alkalization of the cytoplasm also regulates ethylene-induced stomatal closure [5]. Cross-reactions are known to exist between these signaling molecules. It is not known whether additional signaling molecules are involved in the process of stomatal closure induced by ethylene. It is reported that $\mathrm{H}_{2} \mathrm{~S}$ counteracts the oxidative burst generated by $\mathrm{H}_{2} \mathrm{O}_{2}$ production in response to different stresses by reducing $\mathrm{H}_{2} \mathrm{O}_{2}$ concentration and increasing the activity of antioxidant enzymes $[11,20,21]$. This result indicates that an interaction occurs between $\mathrm{H}_{2} \mathrm{~S}$ and $\mathrm{H}_{2} \mathrm{O}_{2}$ in signal pathways. Ethyleneinduced NO synthesis appeared to occur later than that of $\mathrm{Ca}^{2+}$ increase and alkalization of the cytoplasm, which indicates $\mathrm{H}_{2} \mathrm{~S}$ production is not an early ethylene-signaling event such as alkalization of the cytoplasm and $\mathrm{Ca}^{2+}$ increase; as stated earlier, $\mathrm{H}_{2} \mathrm{~S}$ is probably acting on different targets in guard cells.

Further studies are needed to explore further the mechanism of $\mathrm{H}_{2} \mathrm{~S}$ synthesis. The other challenges for future research will be investigation of other components involved in this process or other sources of $\mathrm{H}_{2} \mathrm{~S}$ in ethylene-induced stomatal closure.

This work was supported by the National Natural Science Foundation of China (30970288 and 31170237), the Shandong Provincial Natural Science Foundation (ZR2010CM024), and the Foundation of State Key Laboratory of Plant Physiology and Biochemistry (SKLPPBKF09001).

1 Gao W, Shang Z L. Role of cytosolic ions in stomatal movement (in Chinese). Chin Bull Bot, 2010, 45: 632-639

2 Wang S W, Wang W, Li H X, et al. Function of guard cell photosynthesis in light regulation of stomatal movements (in Chinese). Plant
Physiol Commun, 2010, 46: 499-504

3 Liu G H, Hou L X, Liu J, et al. Nitric oxide induced by hydrogen peroxide mediates ethylene-induced stomatal closure of Arabidopsis thaliana. Proc Natl Acad Sci USA, 2009, 19: 8-18

4 Liu G H, Liu J, Hou L X, et al. NO may function in the downstream of $\mathrm{Ca}^{2+}$ in ethylene induced stomatal closure in Vicia faba L. (in Chinese). Fen Zi Xi Bao Sheng Wu Xue Bao, 2009, 42: 145-155

5 Liu J, Liu G H, Hou L X, et al. Ethylene-induced nitric oxide production and stomatal closure in Arabidopsis thaliana depending on changes in cytosolic pH. Chinese Sci Bull, 2010, 55: 2403-2409

6 Cao Z, Huang B, Wang Q, et al. Involvement of carbon monoxide produced by heme oxygenase in ABA-induced stomatal closure in Vicia faba and its proposed signal transduction pathway. Chinese Sci Bull, 2007, 52: 2365-2373

7 Lamattina L, Polacco J C. Nitric oxide in plant growth, development and stress physiology. Plant Cell Monogr, 2007, 6: 1-5

8 Mustafa A K, Gadalla M M, Snyder S H. Signaling by gasotransmitters. Sci Signal, 2009, 2: 1-17

9 Rausch T, Wachter A. Sulfur metabolism: A versatile platform for launching defence operations. Trends Plant Sci, 2005, 10: 503-509

10 Kimura H. Hydrogen sulfide as a neuromodulator. Mol Neurobiol, 2002, 26: 13-19

11 Zhang H, Tang J, Liu X P, et al. Hydrogen sulfide promotes root organogenesis in Ipomoea batatas, Salix matsudana and Glycine max. J Integr Plant Biol, 2009, 51: 1086-1094

12 Sekiya J, Schmid T A, Wilson L G, et al. Emission of hydrogen sulfide by leaf tissue in response to $L$-cysteine. Plant Physiol, 1982, 70: $430-436$

13 Riemenschneider A, Nikiforova V, Hoefgen R, et al. Impact of elevated $\mathrm{H}_{2} \mathrm{~S}$ on metabolite levels, activity of enzymes and expression of genes involved in cysteine metabolism. Plant Physiol Biochem, 2005, 43: 473-483

14 Gonugunta V K, Srivastava N, Raghavendra A S. Cytosolic alkalinization is a common and early messenger preceding the production of ROS and NO during stomatal closure by variable signals, including abscisic acid, methyl jasmonate and chitosan. Plant Signal Behav, 2009, 4: 561-564

15 Shanghai Institute of Plant Physiology, the Chinese Academy of Sciences, Shanghai Society for Plant Physiology. Modern Plant Physiology Experiment Guide (in Chinese). Beijing: Science Press, 1999

16 Abe K, Kimura H. The possible role of hydrogen sulfide as an endogenous neuromodulator. J Neurosci, 1996, 16: 1066-1071

17 Lisjak M, Srivastava N, Teklic T, et al. A novel hydrogen sulfide donor causes stomatal opening and reduces nitric oxide accumulation. Plant Physiol Biochem, 2010, 48: 931-935

18 Wang P C, Du Y Y, Song C P. Research progress on nitric oxide signaling in plant cells (in Chinese). Chin Bull Bot, 2009, 44: 517-525

19 Hosoki R, Matsuki A N, Kimura H. The possible role of hydrogen sulfide as an endogenous smooth muscle relaxant in synergy with nitric oxide. Biochem Biophys Res Commun, 1997, 237: 527-531

20 Zhang $\mathrm{H}, \mathrm{Hu} \mathrm{L} \mathrm{Y}, \mathrm{Hu} \mathrm{K} \mathrm{D}$, et al. Hydrogen sulfide promotes wheat seed germination and alleviates the oxidative damage against copper stress. J Integr Plant Biol, 2008, 50: 1518-1529

21 Zhang $\mathrm{H}$, Jiao H, Jiang C X, et al. Hydrogen sulfide protects soybean seedlings against drought-induced oxidative stress. Acta Physiol Plant, 2010, 32: 849-857

Open Access This article is distributed under the terms of the Creative Commons Attribution License which permits any use, distribution, and reproduction in any medium, provided the original author(s) and source are credited. 